\title{
PARÂMETROS TOPOGRÁFICOS E A DISTRIBUIÇÃO ESPACIAL DOS ESCORREGAMENTOS RASOS NO BAIRRO DE NOVA DESCOBERTA, REGIÃO METROPOLITANA DO RECIFE (PE)
}

\author{
John Kennedy Ribeiro Santana ${ }^{(a)}$, Joaquim Pedro de Santana Xavier ${ }^{(b)}$, Fabrizio de Luiz Rosito \\ Listo $^{(\mathrm{c})}$
}

(a)Discente do Departamento de Ciências Geográficas, UFPE, E-mail: santanajohn87@ gmail.com;

(b) Discente do Departamento de Ciências Geográficas, UFPE, E-mail: joaquimpedro05@ gmail.com;

${ }^{(c)}$ Docente do Departamento de Ciências Geográficas da UFPE, E-mail: fabrizio.listo@ufpe.br

\section{EIXO: GEOGRAFIA FÍSICA E DESASTRES NATURAIS}

\begin{abstract}
RESUMO
Na Região Metropolitana do Recife é comum a ocorrência de escorregamentos em áreas de risco densamente ocupadas, principalmente em períodos de elevada pluviometria. Nesse contexto, destacase o bairro de Nova Descoberta (zona norte do Recife), que se caracteriza por apresentar encostas com declividades elevadas e intensa ocupação antrópica. Sendo os parâmetros topográficos um dos principais fatores condicionantes de escorregamentos na paisagem, o objetivo principal deste trabalho é avaliar o papel dos parâmetros declividade, orientação, formas da encosta e área de contribuição na deflagração de escorregamentos translacionais rasos em áreas densamente ocupadas do bairro. Para cumprir este objetivo foram gerados os mapeamentos topográficos a partir de um Modelo Digital do Terreno que foram sobrepostos ao mapa de ocorrências de escorregamentos. Os resultados demonstraram que houve maior número de escorregamentos em encostas declivosas, orientadas para sul, sudeste e norte, convexas e com baixos valores de área de contribuição.
\end{abstract}

Palavras chave: Escorregamentos; Parâmetros topográficos; Sistema de Informações Geográficas; Região Metropolitana do Recife.

\section{Introdução}

A organização desigual de muitas regiões metropolitanas do país teve como uma de suas consequências, a ocupação de áreas de risco por populações de menor poder aquisitivo, tais como encostas muito declivosas e margens de rios; situação que vem contribuindo para o aumento de assentamentos precários em áreas impróprias para moradia (FERNANDES et al, 2002; CARVALHO et al 2007, entre outros). O município do Recife é composto, em relação a sua área total, de aproximadamente, 65\% de áreas de morros (ALHEIROS et al, 2003); sendo os escorregamentos nesses locais um dos grandes problemas encontrados na cidade. De acordo com a Defesa Civil do Recife, existem cerca de 140 áreas de risco alto a escorregamentos nos morros da cidade (DEFESA CIVIL DO RECIFE, 2016).

Nesse contexto, destaca-se o bairro de Nova Descoberta (zona norte do Recife), que se caracteriza por apresentar encostas com declividades elevadas e intensa ocupação antrópica. A Defesa Civil do Recife 
vem registrando vários eventos de escorregamentos nesta região, onde são realizados monitoramentos e ações mitigatórias nas áreas densamente ocupadas. Sendo os parâmetros topográficos um dos principais fatores condicionantes de escorregamentos na paisagem, o objetivo principal deste trabalho é avaliar o papel dos parâmetros declividade, orientação, formas da encosta e área de contribuição na deflagração de escorregamentos translacionais rasos em áreas densamente ocupadas no bairro de Nova Descoberta.

\section{2. Área de estudo}

O bairro de Nova Descoberta possui uma população de 34 mil habitantes distribuídos em uma área de $1,8 \mathrm{~km}^{2}$ e caracteriza-se por ser uma região de classe média a baixa, classificado como um dos bairros com maiores índices de exclusão social do Recife (FUNDAJ, 2007; PREFEITURA DO RECIFE, 2016). Está inserido na unidade geomorfológica dos tabuleiros costeiros, cuja dissecação do relevo em direção a costa permitiu a formação de colinas arredondadas e morros sinuosos (ALHEIROS, 1998), com altitudes que variam de $13 \mathrm{~m}$ a $91 \mathrm{~m}$. A região foi formada por sedimentos terciários da Formação Barreiras, típicos de deposição fluvial e apresenta solos com camadas mais arenosas na base e arenosas e argilosas intercaladas nos topos com elevado teor de feldspato, sujeitos a processos de argilização em clima quente e úmido, propícios a escorregamentos (ALHEIROS et al, 2004).

O clima da região caracteriza-se por ser quente e úmido com precipitação média anual de 2000 $\mathrm{mm}$, tendo seu pico nos meses de junho e julho (INSTITUTO NACIONAL DE METEOROLOGIA, 2016). Destaca-se também, que a vegetação original de Mata Atlântica foi desmatada, sendo substituída por vários trechos de solos expostos e vegetação secundária de pequeno porte.

\section{Materiais e métodos}

\section{Ocorrências de escorregamentos}

As ocorrências dos escorregamentos foram obtidas por meio de banco de dados fornecidos pela Defesa Civil do Recife, com pontos georreferenciados dos eventos entre os anos de 2013 e 2016, dos quais foram registradas 90 ocorrências. Tais pontos foram geocodificados na base cartográfica do distrito para posterior análise com os parâmetros topográficos.

\section{Parâmetros topográficos e análise conjunta}

Todos os mapas topográficos gerados tiveram como base um MDT (Modelo Digital do Terreno), com resolução de $1 \mathrm{~m}^{2}$, elaborado por meio de informações planialtimétricas adquiridas no ESIG Recife (Informações Geográficas do Recife), utilizando-se a ferramenta Topo to Raster (software ArcGIS). O mapa de declividade foi gerado a partir da ferramenta Raster Surface (ferramenta 3D Analyst), no qual foram classificados três intervalos de declividade, de acordo com Lei Lehman (Lei Federal n. 6.766/79), 
que afirma que a ocupação urbana é permitida no intervalo de $0^{\circ}-9,6^{\circ}$ de declividade, no segundo intervalo $\left(9,7^{\circ}-16,7^{\circ}\right)$ são necessários laudos e análises técnicas para a ocupação e no terceiro intervalo $\left(>16,8^{\circ}\right)$ não é permitida a ocupação. Ainda utilizando a ferramenta Raster Surface, gerou-se um mapa de orientação das encostas (aspecto), indicando as direções da rosa dos ventos (N, NE, E, SE, S, SW, W, NW) para as quais as encostas estão voltadas. Com a mesma ferramenta, elaborou-se o mapa de formas das encostas (côncavas, retilíneas e convexas). Aplicando a ferramenta Flow Direction foi elaborado o mapa de área de contribuição, classificado por $\log 10\left(\mathrm{~m}^{2}\right)$, indicando a concentração dos fluxos superficiais e subsuperficiais da drenagem (RAMOS et al, 2004).

Por fim, para a análise final do papel dos parâmetros topográficos na deflagração dos escorregamentos, cada mapa (declividade, orientação, formas e área de contribuição) foi sobreposto ao mapa de ocorrências de escorregamentos para o cálculo do índice Concentração de Escorregamentos (CE): razão entre o número de células de cada classe afetada (ex. curvatura côncava) pelos pontos de escorregamentos e o total de células do distrito. Foi também calculado o índice Frequência de Distribuição (FD) com a distribuição percentual das classes de cada mapa topográfico.

\section{Resultados e Discussões}

A maior parte do distrito de Nova Descoberta é composta por áreas declivosas $\left(>16,8^{\circ}\right)$ cuja ocupação é proibida de acordo com a Lei Lehman, apresentando uma Frequência de Distribuição (FD) de aproximadamente 55\% nesta classe (Figura 1 e Figura 2). Das 90 ocorrências de escorregamentos registrados pela Defesa Civil, cerca de $80 \%$ coincidiram também com esta classe, apresentando, portanto, uma elevada Concentração de Escorregamentos (CE) conforme a Figura 1 e a Figura 2.

Com relação à orientação das encostas, o distrito apresenta uma FD relativamente homogênea entre todas as classes e uma CE mais significativa para as encostas voltadas para os quadrantes Sul (S), Norte (N) e especialmente para Sudeste (SE) com aproximadamente 30\% nesta última classe (Figura 1 e Figura 2). Embora possa se considerar que a orientação das encostas possua provavelmente um papel de menor influência na deflagração dos escorregamentos, este parâmetro pode condicionar o teor de umidade sobre o terreno, interferindo em processos biofísicos (ex. tipo de vegetação e espessura do solo).

As encostas convexas apresentaram a maior FD (aproximadamente 60\%) e o maior índice de CE com cerca de $70 \%$ (Figura 1 e Figura 2). Embora as encostas convexas apresentem a maior estabilidade topográfica, conforme consagrado pela literatura geomorfológica, as construções de moradias irregulares presentes nestas encostas podem ter alterado sua estabilidade original tornando-as mais suscetíveis aos escorregamentos. Destaca-se também o fato das encostas côncavas terem apresentado uma FD de apenas $3 \%$, porém uma CE de aproximadamente $10 \%$, isto é, apesar da baixa frequência desta classe no distrito, 


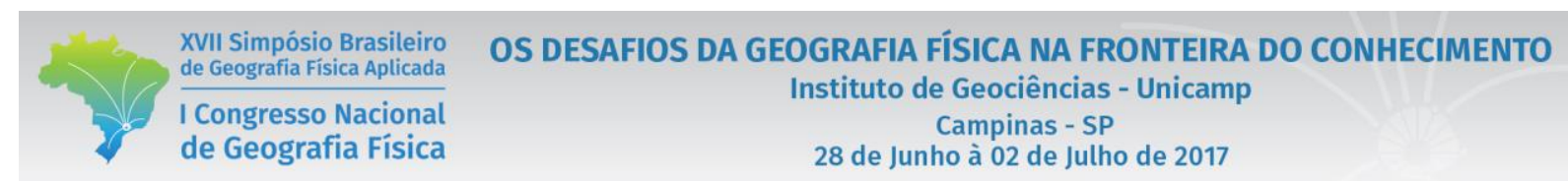

muitos escorregamentos foram deflagrados neste tipo de encostas, confirmando a menor instabilidade de feições côncavas, que tendem a concentrar maior volume de água e de sedimentos durante eventos pluviométricos intensos (Figura 1 e Figura 2).

Por fim, com relação ao parâmetro área de contribuição, há maior FD nas classes de maior valor $\left(35 \log 10 \mathrm{~m}^{2}\right.$ e $64 \log 10 \mathrm{~m}^{2} / 65 \log 10 \mathrm{~m}^{2}$ e $\left.130 \log 10 \mathrm{~m}^{2}\right)$ com índices superiores a $20 \%$. Entretanto, de forma não esperada, a maior CE (cerca de 30\%) ocorreu na classe de menor área de contribuição $\left(1 \log 10 \mathrm{~m}^{2}\right.$ e $\left.4 \log 10 \mathrm{~m}^{2}\right)$, indicando que apesar de haver menor acumulação de fluxos de água, esta classe coincide com áreas de maior declividade, situação que possivelmente influenciou na deflagração dos escorregamentos no distrito (Figura 1 e Figura 2).

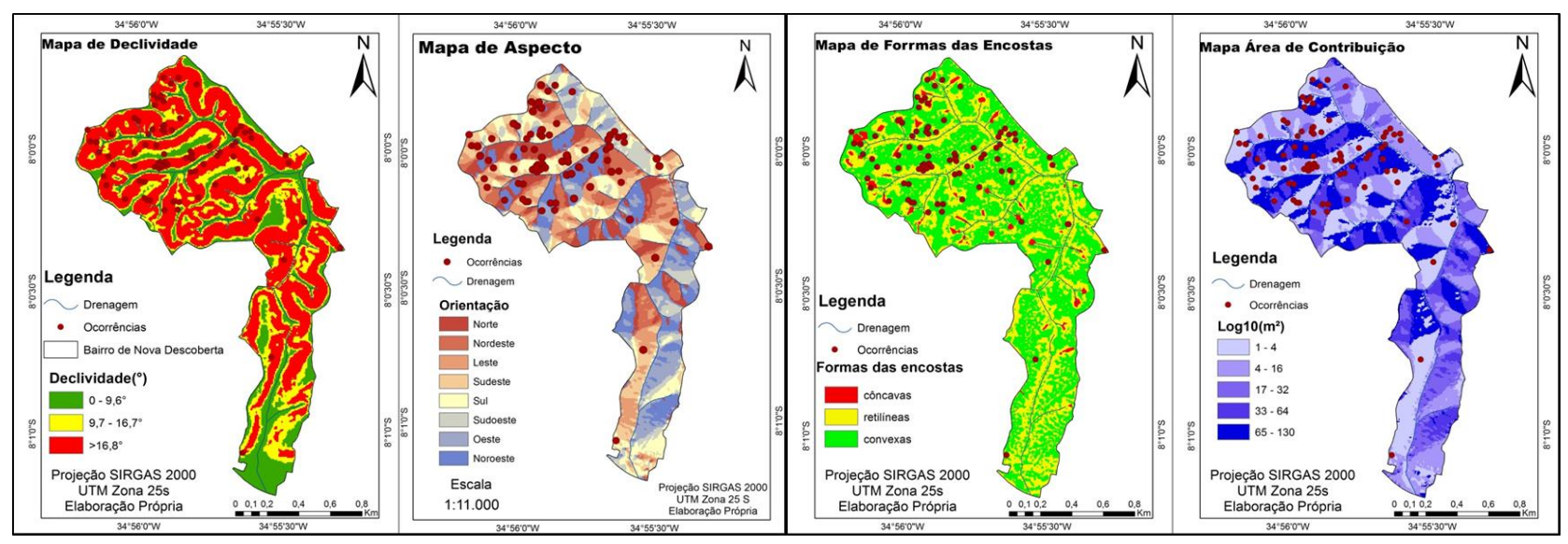

Figura 01 - Mapas Topográficos sobrepostos às ocorrências de escorregamentos: Declividade, Aspecto, Formas e Área de Contribuição. 


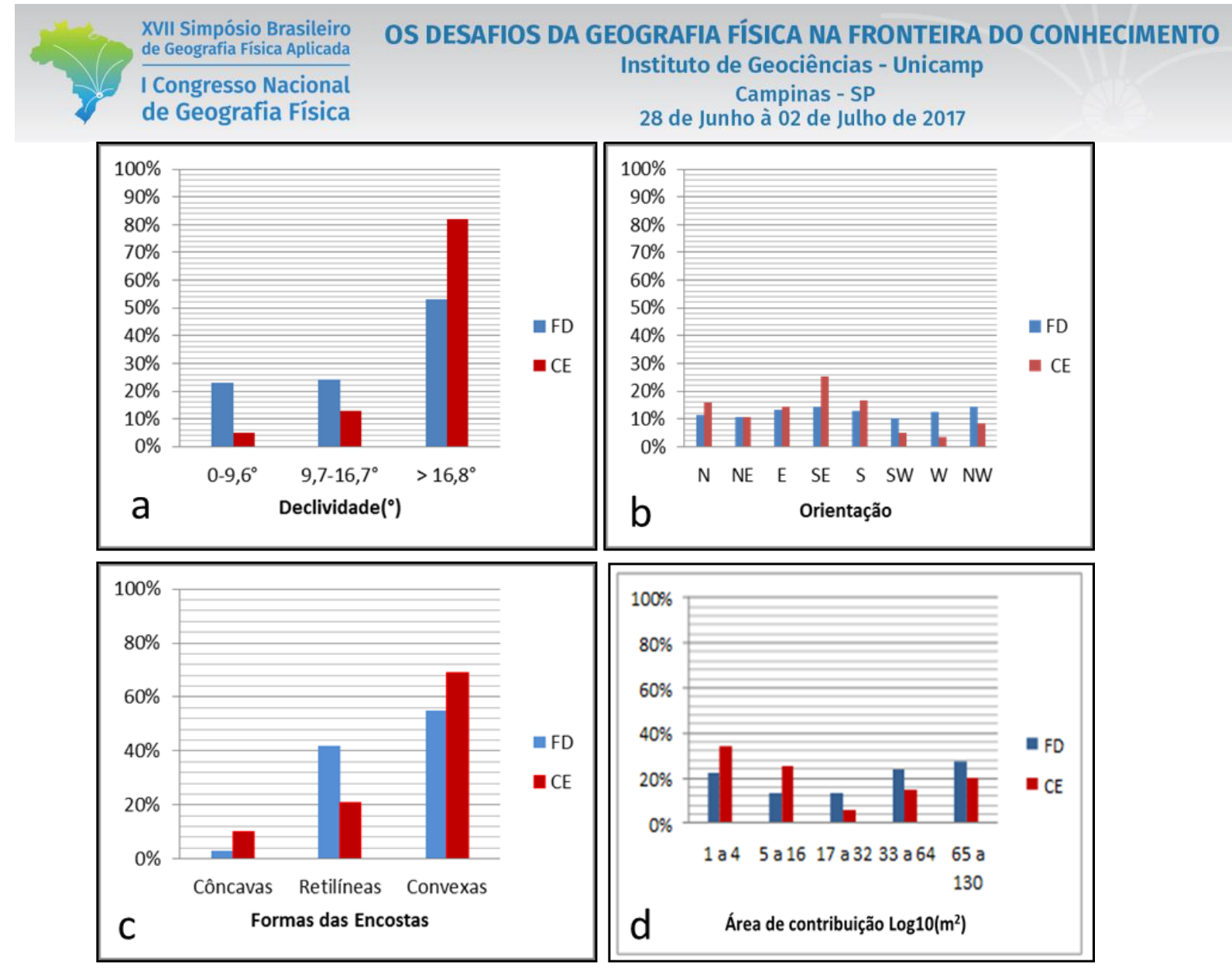

Figura 02: Histogramas de Declividade (a); Orientação (b); Formas da Encosta (c) e Área de Contribuição (d) com os respectivos percentuais de Frequência de Distribuição (FD) e Concentração de Escorregamentos (CE).

\section{Considerações Finais}

Apesar da existência de diversos fatores condicionantes, os parâmetros topográficos se mostram relevantes na análise da suscetibilidade e na deflagração de escorregamentos, principalmente com o desenvolvimento e a difusão dos Sistemas de Informação Geográfica (SIG). Dessa forma, os principais resultados deste trabalho apontaram que as encostas mais declivosas concentraram o maior número de escorregamentos, conforme já amplamente discutido em muitas pesquisas geomorfológicas, bem como em áreas orientadas para os quadrantes sul, sudeste e norte.

Ademais, de forma menos convencional, foram verificadas maiores concentrações de escorregamentos em encostas convexas e com menor valor de área de contribuição; indicando, possivelmente, que outros parâmetros naturais e/ou antrópicos possam ter condicionado a deflagração dos escorregamentos na área e que estudos futuros serão necessários para a compressão total dos processos.

\section{Referências Bibliográficas}


ALHEIROS, M.M. Risco de escorregamentos na Região Metropolitana do Recife. Tese (Doutorado) - Geologia Sedimentar, UFBA, Salvador - BA, 129pp, 1998.

ALHEIROS, M. M.; SOUZA, M. Â. A.; BITOUN, J; MEDEIROS, S. M. G. M.; JÚNIOR, W. M. A. Manual de Ocupação dos Morros da Região Metropolitana do Recife. Fundação de Desenvolvimento Municipal FIDEM; coord. Margareth Mascarenhas Alheiros... (et al.). - Recife: Ensol, p. 11, 2004.

CARVAlHO, C. S.; OGURA; A. T.; MACEDO, E. S. Mapeamento de Risco em Encostas e Margens de Rios. Ministério das Cidades / Instituto de Pesquisas Tecnológicas - IPT, p. 9-32, 2007.

FERNADES, N. F; GUIMARÃES, R. F; GOMES, R. A; VIEIRA, B.C; MONTGOMERY, D. R; GREENBERG, H. Condicionantes Geomorfológicos dos Deslizamentos nas Encostas: Avaliação de Metodologias e Aplicação de Modelo de Previsão de Áreas Susceptíveis. Revista Brasileira de Geomorfologia, v.2, n.1, 2002.

FUNDAJ (FUNDAÇÃO JOAQUIM NABUCO). Mapa de Exclusão/Inclusão Socioambiental do Recife. FUNDAJ: Recife, 2007.

INSTITUTO NACIONAL DE METERIOLOGIA (IMMET). Climatologia dos Meses e Trimestres de Maiores ou Menores Temperaturas e Pluviosidades médias no período de 1961-2009. Disponível em: http://www.inmet.gov.br/portal/index.php?r=clima/mesTempo. Acesso em: 10/02/17; 2016.

RAMOS, V.M.; GUIMARÃES, R. F.; REDIVO, A. L.; CARVALHO, J. O. A.; FERNANDES, F. N.; GOMES, R. A. T. Avaliação de Metodologias de Determinação do Cálculo de Áreas de Contribuição. Revista Brasileira de Geomorfologia, a.4, n. 2, 2003.

DEFESA CIVIL DO RECIFE. Após chuva, Recife registra 140 áreas com alto risco de deslizamento. Disponível em: http://g1.globo.com/pernambuco/noticia/2016/05/apos-chuva-recife-registra-140-areas-com-alto-risco-dedeslizamento.html. Acesso em 11/02/17; 2016.

PREFEITURA DO RECIFE. Serviços Para o Cidadão. Disponível em: http://www2.recife.pe.gov.br/servicos/cidadao. Acesso em 11/02/17; 2016. 